\title{
Disease and Numerical Analysis of Cement Concrete Overlay of a Second-level Road4
}

\author{
Yacan Liu ${ }^{1, a}$,Jianming Yang ${ }^{2, b}$ Chao $\mathrm{He}^{3, \mathrm{c}}$ \\ ${ }^{1}$ Institute of Urban Construction, University of South China, Hengyang, Hunan 421001,China \\ ${ }^{2}$ Institute of Urban Construction, University of South China, Hengyang, Hunan 421001,China \\ ${ }^{3}$ Institute of Urban Construction, University of South China, Hengyang, Hunan 421001,China \\ a446887405@qq.com, b19873605@qq.com, ${ }^{\mathrm{c} 695803447 @ q q . c o m}$
}

Keywords: cement concrete overlay, plate width divided, overlay disease, finite element analysis. Abstract. According to disease investigation and analysis of cement concrete overlay of G322 secondary road, analysis model is built by ABAQUS finite element software, vehicle load stress, temperature stress and uneven settlement of widening subgrade and other external factors of cement overlay are considered, analysis shows that the causes of longitudinal cracks of Scheme A cement concrete overlay is associated with the uneven settlement of widening subgrade, the causes of transverse cracks of local $10 \mathrm{~m}$ cement concrete plate of scheme B is that the plate length is too long, the temperature stress is too high, scheme $\mathrm{B}$ is better mechanical properties and longer life than the scheme A. Guiding suggestions is proposed for design of secondary highway cement concrete pavement overlay.

\section{Introduction}

Highway disease severely affected the functionality of cement concrete pavement.For G322 highway (Three Tong of south Heng - Qidong White City Section) investigate the operations situation of the paving cement concrete surface layer on Old Cement Concrete Pavement, use ABAQUS finite element analysis software for modeling, analyze the disease of cement concrete overlay and causes , and provide design and construction basis for Related fields.

\section{G322 road overlay Disease Investigation.}

G322 line originally was XiangGui road, constructed piece by piece before the war, in the subsequent operation time, it has been renovated several times. In the late 1990s, the rebuilding and widening of the road subgrade carried out .After the renovation was completed, for the serious damage of cement concrete pavement, there was pavement plate crack, void subsidence, dislocation and other diseases everywhere.

Since 2005, G322 road pavement has been overhauled, for some old cement concrete pavement sections thai is not so seriously damaged, such as concrete pavement in the road of south Heng three Tong to Qidong white City section, use the way of paving cement concrete pavement overlay to protect it, its width is $11 \mathrm{~m}$, firstly pave a layer of barrier asphalt felt, and then pave $30 \mathrm{~cm}$ C35 cement concrete surface on it.Keep the width of the roadbed unchanged(12). Cement concrete overlay is formed by two lateral panels or three panels. paving program A: $5.5 \mathrm{~m}+5.5 \mathrm{~m}=11 \mathrm{~m}$; plan B: $4.0 \mathrm{~m}+$ $3.0 \mathrm{~m}+4.0 \mathrm{~m}=11 \mathrm{~m}$. The length of concrete slab is $5 \mathrm{~m}$, in program $\mathrm{B}$ in the middle of the local area ,there are $3 \mathrm{~m}$ wide concrete slab of which the length is $10 \mathrm{~m}$. Partial curve sections get route optimizing, and its subgrade is widened.

Different paving program for cement concrete slab has varying degrees of disease. Usually from the edge of the pavement about $2.0 \mathrm{~m} \sim 2.5 \mathrm{~m}$, there is longitudinal cracks in cement concrete overlayare formed by two lateral panels, especially in curve road, as shown in Fig.1a. In cement concrete overlay formed by three lateral panels, the $5 \mathrm{~m}$ long cement concrete slab is almost integrated.On some pavement, the $10 \mathrm{~m}$ long cement concrete slab has transverse rupture, as shown in Fig.1b. 


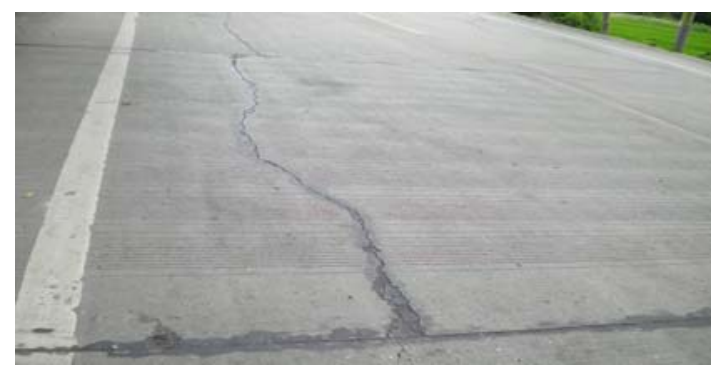

a.Longitudinal cracks

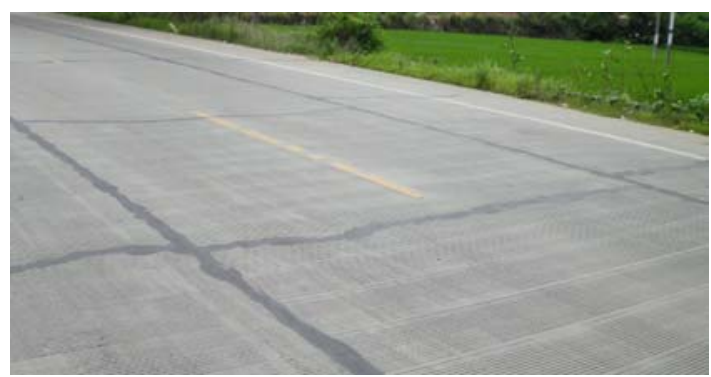

b.Transverse cracks

Figure 1 Disease chart of cement concrete overlay

\section{The calculation model and parameter selection.}

G322 highway pavement structure is followed. $30 \mathrm{~cm}$ C30 cement concrete overlay + Felt $+24 \mathrm{~cm}$ C30 Old Cement Concrete Pavement $+20 \mathrm{~cm}$ Cement stabilized gravel $+16 \mathrm{~cm}$ cement stabilized gravel graded gravel.Cement concrete overlay use separate overlay mode. Scheme A: $5.5 \mathrm{~m}+5.5 \mathrm{~m}=$ $11 \mathrm{~m}$,It is two board overlay mode.Program B: $4.0 \mathrm{~m}+3.0 \mathrm{~m}+4.0 \mathrm{~m}=11 \mathrm{~m}$, It is three board overlay mode.Both plan A, and B are $5 \mathrm{~m}$ long concrete board, only in the program B in the middle of the local area,there is $3 \mathrm{~m}$ wide concrete slab of which the length is $10 \mathrm{~m}$.

In finite element model, highway roadbed height is $1.5 \mathrm{~m}$; slope gradient is $1: 1.5$. Suppose each structural layers are elastic pavement material, the main parameters of the structure layer is shown in Table 1. For load transfer function of tie rod( that is between the concrete slab )of overlay layer, we make use of shear spring unit to simulate the seam[1-2] ,and make use of Friberg theory to calculate the stiffness $q$.

Table 1 pavement structure layer and main parameters of secondary road

\begin{tabular}{cccc}
\hline Layer & Thickness $(\mathrm{m})$ & $\begin{array}{c}\text { elastic modulus } \\
(\mathrm{MPa})\end{array}$ & Poisson's ratio \\
\hline Concrete overlay & 0.30 & 31500 & 0.15 \\
Old pavement & 0.24 & 30000 & 0.15 \\
Cement stabilized gravel & 0.20 & 1400 & 0.20 \\
Graded gravel & 0.16 & 300 & 0.30 \\
Subgrade & 1.50 & 50 & 0.30 \\
\hline
\end{tabular}

\section{The Results of Calculation}

Vehicle Load Stress. Vehicle load is based on the BZZ-100 standard axle load in "cement concrete pavement design specification (JTGD40-2011)"[3]. When the car running in the driveway, road to $0.75 \mathrm{~m}-1.25 \mathrm{~m}$ inside load more, in this context, it under the load almost as many times of $60 \%$ of total number of vehicle axle loads[4] . In the model,it was loaded at vehicle normal driving place and the most unfavorable load position.According to the conventional vehicle wheel tracks frequency distribution in Sideway, assuming normal vehicle load position is the tire position that is $1 \mathrm{~m}$ away from the center line of the road, the most unfavorable load position is middle longitudinal edge of the

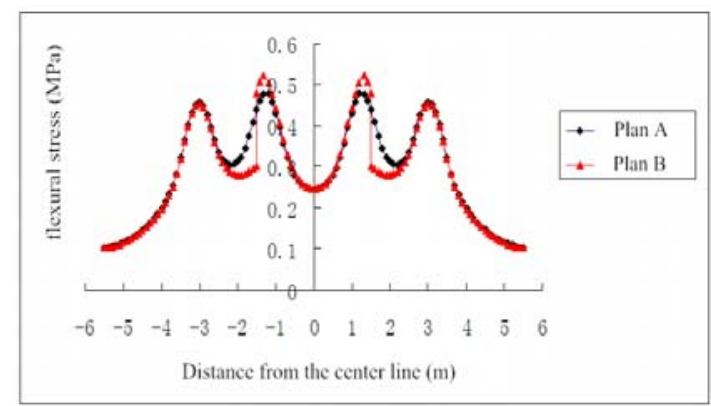

Normal driving

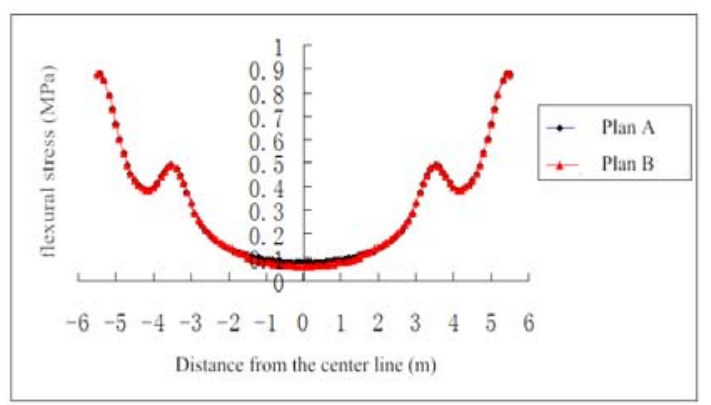

The most unfavorable load position

Figure 2 Laminated flexural stress change chart in vehicle load 
pavement. The results is shown in Fig 2.

Figure 2 shows that during normal driving in the driveway,in plan A flexural tensile stress change stably, the overall stability of the overlay is good, but in plan B overall stability is not good as A. Flexural tensile stress in plan B is at a relatively low level, the impact of plan B is not great on the road.

Flexural tensile under the most unfavorable load position situation is the key point to determine the damage of cement concrete pavement.The flexural stress of concrete overlay between plan A and $\mathrm{B}$ do not have great difference.The stress curves of them almost coincide.when the load in the most unfavorable position, flexural stress in the two programs cement concrete slabs are equal.

Temperature Stress.Because cement concrete pavement at a positive temperature gradient, its temperature warping stress is greater than the negative temperature gradient.,in the model temperature loads are calculated by positive temperature gradient, assume that cement concrete pavement temperature gradient is 88, Linear expansion coefficient is, density is , thermal conductivity of cement concrete is $1.5 \mathrm{~W} /(\mathrm{m} \cdot \mathrm{K})$, specific heat capacity is 0.945 . By finite element analysis, thermal stress of cement concrete overlay is shown in Table 2.

Table 2 Temperature stress of paving scheme A, B (MPa)

\begin{tabular}{cccc}
\hline & $\mathrm{A}$ & $\mathrm{B}$ & $\mathrm{B}$ (partial 10m long blocks) \\
\hline $\begin{array}{c}\text { Intermediate concrete } \\
\text { slab }\end{array}$ & - & 1.203 & 3.537 \\
$\begin{array}{c}\text { Concrete slab on both } \\
\text { sides }\end{array}$ & 1.593 & 1.225 & 1.225 \\
\hline
\end{tabular}

From Table 2, when the concrete slab is $5 \mathrm{~m}$, in plan B concrete slab temperature stress is relatively low ,and maximum temperature stress that is $1.225 \mathrm{MPa}$ is $76 \%$ of concrete slab temperature stress of plan A , it (plan B) can better adapt to the temperature changes . For concrete slab (partial 10m long blocks in plan B), its temperature stress is three times as temperature stress of the $5 \mathrm{~m}$ concrete slab. maximum stress is at the middle of the longitudinal direction, under the influence of temperature stress, concrete slab is prone to transverse rupture.

Cement Concrete Overlay Fatigue Life Calculation. Concrete is different with metal. when the stress is below a certain value, the fatigue life of concrete can be considered infinite.Under the repeated action of the vehicle,cement concrete is without plastic deformation, but the internal cement concrete material may appear slightly cracks. When micro-cracks accumulate to a certain extent,and the stress is below its limit flexural stress, it can also cause concrete slab fracture. With the emergence of many overloaded vehicles, cement concrete pavement is always damaged within a few years in operation. The following formula (double logarithmic equation) to calculate the fatigue life of concrete panels is based on current specification.

$$
\lg \frac{\sigma_{\max }-\sigma_{\min }}{\sigma_{b}-\sigma_{\min }}=\lg a-b \lg N_{f}
$$

$\sigma_{\max }$ : the biggest stress of cement concrete pavement (The superposition value of temperature stress and vehicle load stress); $\sigma_{b}$ :the flexural strength of cement concrete. $\sigma_{\min }$ :temperature stress $(\mathrm{a}=1, \mathrm{~b}=0.057)$.

Table 3 Fatigue life of cement concrete plate of scheme A, B

\begin{tabular}{cccccc}
\hline scheme & $\begin{array}{c}\text { standard axle } \\
\text { load(MPa) }\end{array}$ & $\begin{array}{c}20 \% \text { overload } \\
(\mathrm{MPa})\end{array}$ & $\begin{array}{c}\text { temperature } \\
\text { stress } \\
(\mathrm{MPa})\end{array}$ & $\begin{array}{c}\text { cumulative } \\
\text { standard axle } \\
\text { load } \\
\text { (Axle) }\end{array}$ & $\begin{array}{c}\text { cumulative } \\
\text { 20\% overload } \\
\text { load } \\
\text { (Axle) }\end{array}$ \\
\hline A & 0.879 & 1.055 & 1.593 & $2.10 \mathrm{E}+10$ & $8.55 \mathrm{E}+8$ \\
$\mathrm{~B}(5 \mathrm{~m}$ board $)$ & 0.880 & 1.056 & 1.225 & $1.25 \mathrm{E}+11$ & $5.08 \mathrm{E}+9$ \\
$\mathrm{~B}(10 \mathrm{~m}$ board $)$ & 0.543 & 0.652 & 3.537 & $3.56 \mathrm{E}+7$ & $9.29 \mathrm{E}+5$ \\
\hline
\end{tabular}


In Table 3,Fatigue life of $5 \mathrm{~m}$ concrete overlay of B is $1.25 \mathrm{E}+11$ axle, it is about six times as the paving scheme A therefore cement concrete overlay consisted of three pieces of $5 \mathrm{~m}$-long concrete slab has a longer service life.If calculated by more than $20 \%$ overload and single axle load of $120 \mathrm{KN}$, the fatigue life of overlay has a significant reduction .In operations overload vehicles should be limited. The fatigue life of partial central $10 \mathrm{~m}$ long concrete slab is far below the $5 \mathrm{~m}$ length concrete slab .In the short term it will result in concrete slab fracture.

Roadbed Factors Analysis. Because in highway reconstruction, and curve radius increased, the inside of the subgrade of curve segment is widened, and there is some differential settlement . When we simulate uneven settlement of roadbed, a vertica boundary displacement conditions is loaded in the bottom of the embankment at the boundary in model. Assuming the old roadbed is at the small settlement, in the junction of widened roadbed, the settlement began to increase, to the edge of the road, the settlement amount is to maximum. The wider widened width of roadbed is, the greater the amplitude of uneven subsidence curve change and maximum settlement are. Among different widened roadbed width, maximum settlement location and settlement curve is roughly the same. We simplify generally uneven settlement of roadbed deformation curve to a parabola or sine and cosine curve.This simplification is feasible, and it relatively close to the embankment real deformed[5-7]. When we simulate uneven settlement of roadbed,we assume that no part of the old road lane has differential settlement, the largest settlement is located at road edge,and we make use of cosine curve to calculate differential settlement of widened subgrade beneath the shoulder.

$$
\delta=\delta_{\max } \cos (\pi x / 2 B)
$$

$\delta_{\max }$ :the largest settlement;B:width of widened roadbed. The main factors affecting the pavement structure is the largest settlement of roadbed $\left(\delta_{\max }\right)$ and length of subgrade uneven sedimentation( $\left.\mathrm{L}\right)$. In widened roadbed, the characteristic length $\mathrm{L}$ is the distance of from the junction of the new and old roadbed to the edge of the embankment.At the same time, we define sedimentation variable slope rate $(\Delta i)$. The results are shown in Table 4 .

$$
\Delta i=\frac{\delta_{\max }}{L} .
$$

Table 4 The value of maximum stress of pavement scheme A, B in the uneven settlement

\begin{tabular}{cccc}
\hline$\Delta i$ & $0.1 \%$ & $0.2 \%$ & $0.3 \%$ \\
\hline schemeA(MPa) & 0.389 & 0.826 & 1.244 \\
schemeB(MPa) & 0.365 & 0.771 & 1.159 \\
Difference (\%) & 6.58 & 7.13 & 7.33 \\
\hline
\end{tabular}

In Table 4, the Scheme A concrete slab overlay is hard to adapt for widened subgrade differential settlement .when the settlement is a littlel, the difference of two additional stress between A and B is small.with the settlement increases, stress growth rate of program A rise. When sedimentation variable slope rate is at $0.1 \%$, the difference between $\mathrm{A}$ and $\mathrm{B}$ is $6.58 \%$. when the rate is $0.3 \%$, the gap between the two programs is increased to $7.33 \%$.

\section{Conclusion}

1.The temperature stress of overlay in program A is too large,considered with vehicle load stress, the fatigue life is much lower than plan $\mathrm{B}$. When consider some vehicles overload factor, the scheme B overlay will be better than A.

2.program B Local $10 \mathrm{~m}$ concrete slab has transverse rupture, and the concrete slab length is too long, so there is a sharp increase in temperature stress, and it add to vehicle load stress, resulting in cement concrete overlay has transverse cracks.

3. longitudinal cracks appeare in program A, it is related to widened subgrade differential settlement,embankment reinforcement work should be paid attention in highway reconstruction . 
4. paving cement pavement in secondary old roads, do not to use large concrete slab whose width is greater than $4.5 \mathrm{~m}$ ).We can make use of three concrete slabs or pave the tie rod in the hard shoulder separately.

\section{References}

[1] Zhouzheng Feng, Ling Jianming. [J] based on Traffic and Transportation Engineering, 2009,9 (3) .39-44.(In Chinese)

[2] Zhouzheng Feng, Ling Jianming, Yuan Jie.[J]. China Civil Engineering Journal, 2009,42 (2) 112-118.(In Chinese).

[3] People's Republic of China industry standard cement concrete pavement design specification (JTGD40-2011) [S]. Beijing: China Communications Press, 2011.(In Chinese).

[4] Lu Ding, Cheng Jiaju road embankment engineering [M]. Shanghai: Tongji University Press, 2009.(In Chinese).

[5] Li Chunming.[J]. Northern Jiaotong .2011, (11) .31-33.(In Chinese)

[6] Ying Ronghua, He Wanlin, Jiang Fu. [J]. Highways \& Automotive, 2005, (4) .79-81.(In Chinese)

[7] Zhou Wen[J]. Highway Engineering, 2009,5 (34) .67-74.(In Chinese) 